\title{
CONGESTION MANAGEMENT BY MAXIMIZING THE OVERALL SATISFACTION DEGREE OF ALL PARTICIPANTS IN THE MARKET
}

\author{
Mário Helder Gomes \\ Departamento de Engenharia Electrotécnica \\ Escola Superior de Tecnologia de Tomar \\ Quinta do Contador, Estrada da Serra \\ 2300 Tomar - Portugal \\ mgomes@ipt.pt
}

\author{
J. Tomé Saraiva \\ Fac. de Engenharia da Universidade do Porto \\ and INESC Porto \\ P. República 93, 4050 Porto, Portugal \\ phone +351.2 .2 .2094230 fax +351.2 .2 .2084172$ \\ jsaraiva@,inescn.pt
}

\begin{abstract}
In the scope of the reregulation process of the electric sector, both competitive pool markets and contract mechanisms at the generation and commercialization levels have been emerging. At the wholesale level, and apart from Pool structures and Bilateral Contracts, there are hybrid models in which these two types of structures coexist. In any case, the dispatch coming from the Pool Market Operator, prepared according to the buying and selling offers, together with the bilateral contracted powers must be analyzed from a technical point of view by an independent entity - System Operator. The System Operator aims at checking if the scheduled injected powers do not lead to a decrease of the security standards of the system. Taking in account this concern, in this paper we describe several models to perform the technical validation of sets of electricity schedules, namely trying to minimize the financial impact of the required changes on pre-scheduled generations and loads. This objective is modelled in terms of maximizing the satisfaction degree felt by the participants in the market. The developed application uses Simulated Annealing to solve the corresponding optimization problems. In Section IV of this paper we will include results obtained from several simulations in order to illustrate and demonstrate the interest of the referred models.
\end{abstract}

\section{INTRODUCTION}

The restructuring process of the electric sector has been developing in the last decade in several European countries, in America, both in north and Latin American countries, and in Australia. Basically, it aims at introducing a high level of competitiveness in the generation and in the commercialization of electricity leading to a more decentralized operation of power systems and to an increase of the benefits obtained by all the agents, according to market rules. The EU Directive 96/92 that came into force in February 1999 favours the creation of an European electricity common market by considering some common, yet very general, guidelines to organize the sector in the member states. However, the electric sectors of the EU member states already displayed very different structures by the moment at which the referred Directive was approved. This turned it more difficult to adopt a common set of procedures to facilitate the implementation of the electricity common market. The discussions on the Tariffs on the Use of Networks in case of transnational power flows, organized on what is now known as the Florence Forum, is just an example of the difficulties on this process. In any case and according to the EU Directive, member states are forced to open their networks to third entities either considering published or negotiated Tariffs. More recently, recognizing the different paces adopted by member countries, it was proposed to completely liberalize the supply of electricity for all non domestic supplies till 2003 and for domestic consumers till 2005. This does not represent a major change for some countries in which the liberalization is already more developed but will correspond to a major change - that will have to be done in a short period - for several others.

Given the previous process, it is important to recognize that one needs new computational tools that must be used to guarantee the success of this restructuring process as well as the security and high reliability levels of power system operation. In fact, the presence of multiple agents using the same network, the existence of Pool organizations responsible for a purely economic dispatch [1], and the possibility of establishing Bilateral Contracts clearly leads to a more decentralized set of decisions determining power system operation. Surely, the presence of all these injections in the same period of time in the network can lead to congestion in several branches of the system or can reduce its security operational standards [2],[3]. For this reason, and completing the market mechanisms designed to organize the commercial relationship among several entities, it becomes crucial the existence of coordinating entities in charge of technical issues and of the daily operation of the systems. These entities are named Independent System Operators - ISO and they are responsible for conducting several studies to check whether the injections communicated by the Pool operator or due to physical Bilateral Transactions are feasible in terms of several power system constraints. Congestion management is performed in different ways in different countries but it generally requires some degree of interaction between the System Operator, for one side, and Market Operators and entities responsible for bilateral trades, for the other, in order to change injections in order to alleviate congestion [4 to 8].

Given these concerns, in this paper we describe in Section II four formulations aiming at determining the most adequate procedure to alleviate congestion [9]. They basically correspond to optimization problems to perform a technical validation study of buying/selling electricity contracts. These models will be presented in terms of their increasing complexity so that the last three ones aim at maximizing the satisfaction degree felt by all participants in the market in terms if minimizing the financial impact due to changes on scheduled powers. The implemented application uses the Simulated Annealing metaheuristic to solve those problems given its reduced difficulty of implementation and its ability to escape from local optima. In Section III we present the solution algorithm and in Section IV we will detail 
several implementation issues and present results using a Case Study based on the IEEE 24 test system in order to illustrate the use of these models and to clarify the potential interest of the results. Finally, Section V presents some conclusions of this research.

\section{TECHNICAL VALIDATION MODELS OF BUYING/SELLING POWER CONTRACTS}

A. Model 1 - Minimization of the Square of the Deviations of the Initially Contracted Powers

In this first model we aim at to identifying a new set of contracted powers in such a way that the sum of the squares of the differences among its final and initial values is minimized. The formulation (1) to (7) allows us to identify the new set of contracted powers considering the DC model to translate the operation conditions of the power system.

$$
\begin{array}{ll}
\min & \mathrm{Z}=\sum\left(\Delta \mathrm{Pg}_{\mathrm{ij}}\right)^{2} \\
\text { subj. } & \sum\left(\mathrm{Pg}_{\mathrm{ij}}^{\mathrm{o}}+\Delta \mathrm{Pg}_{\mathrm{ij}}\right)=\mathrm{Pl}_{\mathrm{j}} \\
& \mathrm{Pg}_{\mathrm{i}}^{\min } \leq \sum\left(\mathrm{Pg}_{\mathrm{ij}}^{\mathrm{o}}+\Delta \mathrm{Pg}_{\mathrm{ij}}\right) \leq \mathrm{Pg}_{\mathrm{i}}^{\max } \\
& -\mathrm{P}_{\mathrm{k}}^{\max } \leq \sum \mathrm{a}_{\mathrm{ki}}\left(\sum \mathrm{Pg}_{\mathrm{ij}}^{\mathrm{o}}-\mathrm{Pl}_{\mathrm{i}}+\sum \Delta \mathrm{Pg}_{\mathrm{ij}}\right) \leq \mathrm{P}_{\mathrm{k}}^{\max } \\
& 0 \leq \mathrm{Pg}_{\mathrm{ij}}^{\mathrm{o}}+\Delta \mathrm{Pg}_{\mathrm{ij}} \leq \mathrm{Pl}_{\mathrm{j}} \\
& \sum \mathrm{Cl}\left(\mathrm{Pg}_{\mathrm{ij}}^{\mathrm{o}}+\Delta \mathrm{Pg}_{\mathrm{ij}}\right)-\mathrm{Cg}\left(\sum \mathrm{Pg}_{\mathrm{ij}}^{\mathrm{o}}+\sum \Delta \mathrm{Pg}_{\mathrm{ij}}\right) \geq 0,0 \\
& \Delta \mathrm{Pg}_{\mathrm{ij}} \in \mathfrak{R}
\end{array}
$$

In this formulation:

- $\operatorname{Pg}_{\mathrm{ij}}^{\mathrm{o}}$ represents the initial contracted power between generator $\mathrm{i}$ and load $\mathrm{j}$;

- $\Delta \mathrm{Pg}_{\mathrm{ij}}$ represents the changes on $\mathrm{Pg}_{\mathrm{ij}}^{\mathrm{o}}$ as a result of the technical validation study;

- $\quad \mathrm{Pl}_{\mathrm{j}}$ represents the active load connected to node $\mathrm{j}$;

- $\mathrm{Pg}_{\mathrm{i}}^{\min }$ and $\mathrm{Pg}_{\mathrm{i}}^{\max }$ are the minimum and maximum generations of generator $i$;

- $\mathrm{a}_{\mathrm{ki}}$ is the sensibility coefficient expressing the impact of the injected power in node $\mathrm{i}$ in the active power flow in branch k;

- $\quad \mathrm{P}_{\mathrm{k}}^{\max }$ represents the maximum value of the active power flow in branch $\mathrm{k}$.

Constraints (2) are included to ensure that each load $\mathrm{j}$ is supplied by a set of contracted powers. Constraints (3) and (4) impose the min and max limits on active generations and on active branch flows. Constraints (5) impose the admissible ranges of variation to the contracted power between each generator $\mathrm{i}$ and each load j. Finally, constraints (6) enforce that the modified contracted powers still lead to profits. The profit of generator $\mathrm{i}$ is represented by the difference between:

- the sum of the amounts paid by load $\mathrm{j}$ with which generator $i$ established a contract. The amount each load agreed to pay is represented by the function $\mathrm{Cl}$;

- the generation cost function of generator $\mathrm{i}$ given by $\mathrm{Cg}$.
B. Model 2 - Maximization of the Generators Satisfaction Degree Using the DC Model

Let us consider that at least a technical constraint is violated for the set of initial contracted powers. In order to eliminate that violation and as a result of the technical validation study, positive or negative deviations $\Delta \mathrm{Pg}_{\mathrm{ij}}$ should be imposed on the initial contracted values $\operatorname{Pg}_{\mathrm{ij}}^{\mathrm{o}}$. The objective of the technical validation study will now be to change the initial contracted powers decreasing the profits as little as possible.

In the scope of Fuzzy Sets Theory [10], it is possible to build a membership function of the profit of generator $i, \operatorname{Pr} f_{i}$, expressing the satisfaction degree felt by that generation entity regarding its profits. For this purpose, let us consider that each generating entity admits to decrease the profit associated to the initial contracted values, $\operatorname{Prf}_{\mathrm{i}}^{\mathrm{O}}$, considering at the most a tolerance $\varepsilon$. Using these ideas, in the referred membership function profits larger than $\operatorname{Prf}_{i}{ }^{O}$ are considered fully satisfactory - membership degree 1.0 - while profits smaller than $(1-\varepsilon) \cdot \operatorname{Pr}_{\mathrm{i}}^{\mathrm{o}}$ are assigned a 0 membership degree. Profits between these values have a membership degree in the interval from 0 to 1.0 as it is displayed in Figure 1.

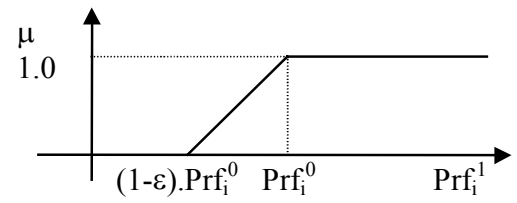

Figure 1 - Membership function of the profit of generator $i$.

According to this reasoning, the technical validation problem will now be formulated in terms of identifying the changes on the initial contracted powers, $\Delta \mathrm{Pg}_{\mathrm{ij}}$, so that the global satisfaction degree $\mu$ is maximized. This study is now formulated by (8) to (15) considering, once again, the DC model to translate the operation conditions of the power system.

$$
\begin{array}{ll}
\max & \mathrm{Z}=\mu \\
\text { subj. } & \sum\left(\mathrm{Pg}_{\mathrm{ij}}^{\mathrm{o}}+\Delta \mathrm{Pg}_{\mathrm{ij}}\right)=\mathrm{Pl}_{\mathrm{j}} \\
& \mathrm{Pg}_{\mathrm{i}}^{\min } \leq \sum\left(\mathrm{Pg}_{\mathrm{ij}}^{\mathrm{o}}+\Delta \mathrm{Pg}_{\mathrm{ij}}\right) \leq \mathrm{Pg}_{\mathrm{i}}^{\max } \\
& -\mathrm{P}_{\mathrm{k}}^{\max } \leq \sum \mathrm{a}_{\mathrm{ki}}\left(\sum \mathrm{Pg}_{\mathrm{ij}}^{\mathrm{o}}-\mathrm{Pl}_{\mathrm{i}}+\sum \Delta \mathrm{Pg}_{\mathrm{ij}}\right) \leq \mathrm{P}_{\mathrm{k}}^{\max } \\
& 0 \leq \mathrm{Pg}_{\mathrm{ij}}^{\mathrm{o}}+\Delta \mathrm{Pg}_{\mathrm{ij}} \leq \mathrm{Pl}_{\mathrm{j}} \\
& \operatorname{Prf}_{\mathrm{i}}^{1} \geq(1-\varepsilon) \operatorname{Pr}_{\mathrm{i}}^{\mathrm{o}}+\mu \varepsilon \operatorname{Prf}_{\mathrm{i}}^{\mathrm{o}} \\
& 0,0 \leq \mu \leq 1,0 \\
& \Delta \mathrm{Pg}_{\mathrm{ij}} \in \Re
\end{array}
$$

In this formulation $\mathrm{Pl}_{\mathrm{j}}, \mathrm{Pg}_{\mathrm{i}}^{\min }$ and $\mathrm{Pg}_{\mathrm{i}}^{\max }, \mathrm{a}_{\mathrm{ki}}$ and $\mathrm{P}_{\mathrm{k}}^{\max }$ have the meaning already indicated in Section II. A. Constraints (9), (10), (11) and (12) are similar to the corresponding ones already included in the model of Section II. A. Constraints (13) are included to assure that the profit of generator $\mathrm{i}$ is not reduced more than the value related to the referred tolerance. Since the 
objective function corresponds to maximize the membership degree of the profit, we are in fact trying to alleviate the violated constraints while reducing the profits as little as possible.

This formulation is similar to the model in Section II. A. except in what regards the objective function - now we are maximizing the membership degree of the profit - and constraints (13). These constraints are essentially different from the ones in the model of Section II. A. The ones in the model in Section II. A correspond in fact to impose 0.0 as the minimum limit on the profit of each generator. This means that, as results, one may obtain large changes in the profits, some ones being largely reduced while other ones being eventually very much increased. The model (8) to (15) overcomes this problem by considering a tolerance on the profit change and by maximizing the membership degree of the profit.

C. Model 3 - Maximization of the Generators Satisfaction Degree Using the AC Model and Bilateral Contracts

The previous formulation can be modified in order to integrate the AC power flow model thus leading to (16) to (28).

$$
\begin{array}{ll}
\max & \mathrm{z}=\mu \\
\text { subj } & \mathrm{Pg}_{\mathrm{k}}-\mathrm{Pl}_{\mathrm{k}}=\mathrm{f}_{\mathrm{l}}(\mathrm{V}, \theta) \\
& \mathrm{Qg}_{\mathrm{k}}-\mathrm{QL}_{\mathrm{k}}=\mathrm{f}_{2}(\mathrm{~V}, \theta) \\
& -\mathrm{P}_{\mathrm{k}}^{\max } \leq \mathrm{f}_{3}(\mathrm{~V}, \theta) \leq \mathrm{P}_{\mathrm{k}}^{\max } \\
& \mathrm{V}_{\mathrm{k}}^{\min } \leq \mathrm{V}_{\mathrm{k}} \leq \mathrm{V}_{\mathrm{k}}^{\max } \\
& \mathrm{Pg}_{\mathrm{i}}^{\min } \leq \mathrm{Pg}_{\mathrm{i}}^{1} \leq \operatorname{Pg}_{\mathrm{i}}^{\max } \\
& \operatorname{Pg}_{\mathrm{i}}^{1}=\sum\left(\operatorname{Pg}_{\mathrm{ij}}^{\mathrm{o}}+\Delta \mathrm{Pg}_{\mathrm{ij}}\right)+\operatorname{Ploss}_{\mathrm{i}} \\
& \sum \mathrm{Ploss}_{\mathrm{i}}=\sum \mathrm{f}_{4}(\mathrm{~V}, \theta) \\
& \sum\left(\operatorname{Pg}_{\mathrm{ij}}^{\mathrm{o}}+\Delta \operatorname{Pg}_{\mathrm{ij}}\right)=\mathrm{Pl}_{\mathrm{j}} \\
& 0,0 \leq \operatorname{Pg}_{\mathrm{ij}}^{\mathrm{o}}+\Delta \operatorname{Pg}_{\mathrm{ij}} \leq \mathrm{Pl} \mathrm{j} \\
& \operatorname{Pr}_{\mathrm{i}}^{1} \geq(1-\varepsilon) \operatorname{Pr}_{\mathrm{i}}^{\mathrm{o}}+\mu \varepsilon \operatorname{Pr}_{\mathrm{i}}^{\mathrm{o}} \\
& 0,0 \leq \mu \leq 1,0 \\
& \Delta \operatorname{Pg}_{\mathrm{ij}} \in \mathfrak{R}
\end{array}
$$

In this formulation, (17) and (18) correspond to the equations of the $\mathrm{AC}$ power flow model considering that $\mathrm{fl}$ and f2 represent the expressions of the active and reactive injected powers. Constraints (19) correspond to the limits of the active power flow in each branch, given that $\mathrm{f} 3$ is the expression of the active power flow in branch $k$. Constraints (20) and (21) impose the minimum and maximum values on the voltage magnitude and on each active generation. Constraints (22) correspond to the expressions of each active generation in terms of the initial contracted powers and of the changes imposed on those contracts by the technical validation study. In these expressions it is also included a term that represents the active power to generate in each generator as its contribution to compensate the active power losses. The sum of these contributions in all generators must equal the global value of the active power losses. In this sense, in constraint (23) function f4 represents the expression of the active power losses in a branch of the system. Constraints (24) to (28) have a similar meaning as already referred in section II. B.
D. Model 4 - Maximization of the Generators Satisfaction Degree Using the AC Model and Bilateral Contracts and Pool Schedules

Finally, Model 3 can be enhanced including both schedules coming from Bilateral Contracts and from Pool markets. Model 4 is now given by (29) to (44).

$$
\begin{aligned}
& \max \quad z=\mu \\
& \text { subj } P g c_{n}^{1}+\operatorname{Pgp}_{n}^{1}-P_{1} c_{n}-P_{1} p_{n}=f_{1 n}(V, \theta) \text { (for each node } n \text { ) (30) } \\
& \mathrm{Qg}_{\mathrm{n}}-\mathrm{Q} 1_{\mathrm{n}}=\mathrm{f}_{2 \mathrm{n}}(\mathrm{V}, \theta) \\
& -\mathrm{P}_{\mathrm{k}}^{\max } \leq \mathrm{f}_{3 \mathrm{k}}(\mathrm{V}, \theta) \leq \mathrm{P}_{\mathrm{k}}^{\max } \\
& \mathrm{V}_{\mathrm{n}}^{\min } \leq \mathrm{V}_{\mathrm{n}} \leq \mathrm{V}_{\mathrm{n}}^{\max } \\
& \operatorname{Pgp}_{i}^{\min } \leq \operatorname{Pgp}_{i}^{1} \leq \operatorname{Pgp}_{i}^{\max } \\
& \mathrm{Pgc}_{\mathrm{i}}^{\min } \leq \mathrm{Pgc}_{\mathrm{i}}^{1} \leq \mathrm{Pgc}_{\mathrm{i}}^{\max } \\
& \operatorname{Pgc}_{\mathrm{i}}^{1}=\sum_{\mathrm{j}}\left(\mathrm{Pgc}_{\mathrm{ij}}^{\mathrm{o}}+\Delta \mathrm{Pgc}_{\mathrm{ij}}\right)+\operatorname{Ploss}_{\mathrm{i}} \\
& \operatorname{Pgp}_{\mathrm{i}}^{1}=\operatorname{Pgp}_{\mathrm{i}}^{\mathrm{o}}+\Delta \mathrm{Pgp}_{\mathrm{i}}+\mathrm{Ploss}_{\mathrm{i}} \\
& \sum_{\text {and }} \operatorname{Ploss}_{\mathrm{i}}=\sum_{\mathrm{k}} \mathrm{f}_{4 \mathrm{k}}(\mathrm{V}, \theta) \\
& \left.\sum_{\mathrm{i}}\left(\mathrm{Pgc}_{\mathrm{ij}}^{\mathrm{O}}+\Delta \mathrm{Pgc}_{\mathrm{ij}}\right)=\mathrm{Plc}_{\mathrm{j}} \quad \text { (for each load } \mathrm{j}\right) \\
& 0 \leq \mathrm{Pgc}_{\mathrm{ij}}^{\mathrm{O}}+\Delta \mathrm{Pgc}_{\mathrm{ij}} \leq \mathrm{Plc}_{\mathrm{j}} \quad \text { (for each } \mathrm{i} \text { and } \mathrm{j} \text { ) } \\
& \sum_{\mathrm{i}}\left(\mathrm{Pgp}_{\mathrm{i}}^{\mathrm{o}}+\Delta \mathrm{Pgp}_{\mathrm{i}}\right)=\sum_{\mathrm{j}} \mathrm{Plp} \mathrm{p}_{\mathrm{j}} \\
& \operatorname{Pr}_{i}^{1} \geq(1-\varepsilon) \cdot \operatorname{Prf}_{i}^{o}+\mu . \varepsilon \cdot \operatorname{Pr}_{i}^{o} \quad \text { (for each gen. } i \text { ) } \\
& 0.0 \leq \mu \leq 1.0 \\
& \Delta \mathrm{Pg}_{\mathrm{ij}} \in \mathfrak{R}
\end{aligned}
$$

In this formulation active powers having an index $\mathrm{c}$ are related to physical Bilateral Contracts and the ones with an index $\mathrm{p}$ are due to schedules coming from the Pool. The variables $\Delta \operatorname{Pgc}_{\mathrm{ij}}$ and $\Delta \mathrm{Pgp}_{\mathrm{i}}$ represent the deviations coming from the technical validation study for the Bilateral Contract between the generator $i$ and the load $j$ and the deviation to be imposed on the scheduled of generator i coming from the Pool. All constraints are similar to the ones already present in Model 3, except constraints (41). This constraint imposes that the final values allocated to the Pool dispatched generators equal the sum of the loads initially scheduled in the Pool system. This formulation inherently accepts that branch flow or voltage magnitude violations can be addressed either within the Bilateral Contracted powers or within the Pool schedules but these two sets of schedules must remain balanced. This is expressed by constraints (39) for the Bilateral Contracts and by (41) for the Pool powers.

\section{SOLUTION ALGORITHM}

To solve the above described problems we used the Simulated Annealing metaheuristic [11]. This selection was due to its flexibility and easiness of implementation as well as the possibility of obtaining good results, namely given the capacity of Simulated Annealing to escape from local optima. 
The algorithm departs from an initial solution corresponding to the set of initial contractual values for a given trade period. Then, it is established the neighbourhood structure of that solution from which a new solution is sampled. The acceptance of the new solution depends on the evaluation of the fitness function constituted by the objective function of the model in use and by increasing penalty terms as the constraints of the problem are more violated. A new solution is accepted if the value of its fitness function is larger/smaller - depending if we are dealing with a maximization or minimization problem - or, if the sampled solution is worse than the current, if a sampled probability is smaller than the pre-specified probability of acceptance of worse solutions. The iterative process finishes when there is no improvement of the fitness function for a number of iterations larger than a pre-specified value or when the minimum temperature of the cooling process is reached.

Figure 2 presents the simplified algorithm of the Simulated Annealing approach. $\mathrm{w}$ is the worse solutions counter, $\mathrm{n}$ is the number of iterations and $\mathrm{T}$ is the Temperature control parameter. In this Figure $\mathbf{o}$ designates $<$ for a minimization problem and $>$ for a maximization one.

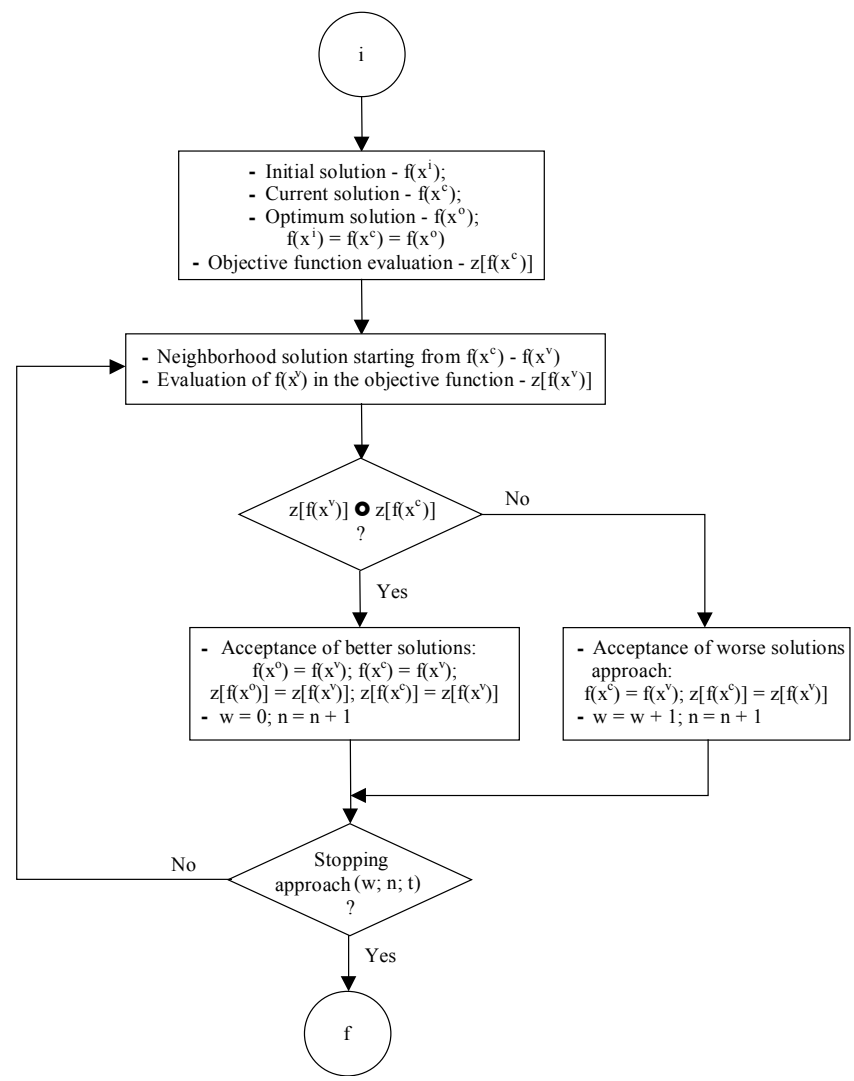

Figure 2 - Simplified solution algorithm.

\section{CASE STUDY}

\section{A. Network Test Data}

The models presented in the Section II were tested using the IEEE test network of 24 bus, represented in the Figure 3. Regarding the data of this network, the loads were increased by $80 \%$ and the maximum value of the generations was doubled relatively the original values of reference [12].

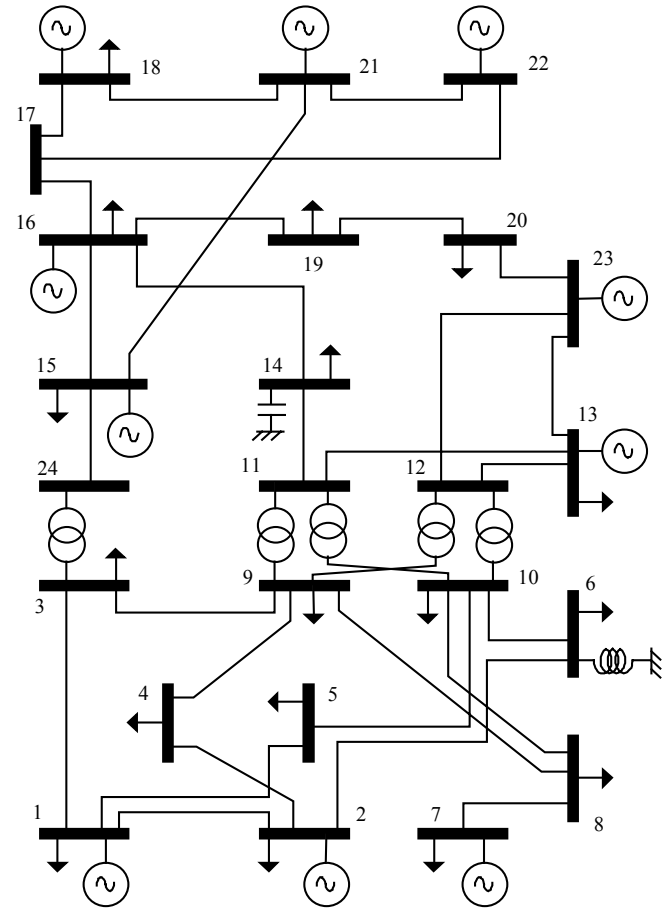

Figure 3 - IEEE Test Network of 24 bus.

The developed Models require the specification of the generator cost functions as well as the load remuneration functions. Regarding generator cost functions we used quadratic functions with parameters $a$ and $b$ as in (45). Regarding load remuneration functions we adopted functions as in (46). In Table I we indicate the coefficients $a$ and $b$ for generator cost functions and $\mathrm{c}$ for load remuneration functions.

$$
\begin{aligned}
& \mathrm{C}_{\mathrm{g}}\left(\mathrm{P}_{\mathrm{g}}\right)=\mathrm{a} \cdot \mathrm{P}_{\mathrm{g}}+\mathrm{b} \cdot \mathrm{P}_{\mathrm{g}}^{2} \\
& \mathrm{C}_{\mathrm{l}}\left(\mathrm{P}_{1}\right)=\mathrm{c} . \mathrm{Pl}
\end{aligned}
$$

Table I - Data for generator cost and load remuneration functions.

\begin{tabular}{|c||c|c||c|}
\hline Bus & $\mathrm{a}$ & $\mathrm{b}$ & $\mathrm{c}$ \\
\hline \hline 1 & 4.00 & 0.003 & 13.00 \\
2 & 3.50 & 0.004 & 12.50 \\
3 & - & - & 11.00 \\
4 & - & - & 15.00 \\
5 & - & - & 15.50 \\
6 & - & - & 13.50 \\
7 & 5.00 & 0.002 & 13.00 \\
8 & - & - & 13.00 \\
9 & - & - & 12.50 \\
10 & - & - & 11.80 \\
13 & 6.00 & 0.003 & 10.60 \\
14 & - & - & 11.00 \\
15 & 2.50 & 0.004 & 10.50 \\
16 & 5.50 & 0.003 & 16.00 \\
18 & 9.00 & 0.001 & 12.00 \\
19 & - & - & 13.40 \\
20 & - & - & 13.60 \\
21 & 8.00 & 0.001 & - \\
22 & 2.00 & 0.004 & - \\
23 & 5.75 & 0.003 & - \\
\hline
\end{tabular}




\section{B. Results Obtained with Model 1}

Table II includes the generations in each bus resulting from the initially established contracts (column 2), the deviations resulting from the technical validation study (column 3 ) and the resulting generations in each bus (column 4). According to the initially established contracts it is immediate to conclude that there would be congestion in line 7-8 since the generation in bus 7 was $535 \mathrm{MW}$, the load in bus 7 is $225 \mathrm{MW}$ and the transmission capacity of that line is $175 \mathrm{MW}$. Since node 7 is connected to the rest of the system only by line 7-8 there would be a congestion of $135 \mathrm{MW}$ is this line. After running the technical validation study, the generation in bus 7 is decreased by $135 \mathrm{MW}$ and this power is reallocated to other generators in a way not to lead to congestion in another branches. Finally, it can be checked that the algebraic sum of the generation deviations is zero, meaning that the global generation and the global load remain balanced.

Table II - Initially contracted generations $\left(\sum \operatorname{Pg}_{\mathrm{ij}}^{\mathrm{o}}\right)$, deviations $\left(\sum \Delta \mathrm{Pg}_{\mathrm{ij}}\right)$ and final generations $\left(\sum \mathrm{Pg}_{\mathrm{ij}}^{1}\right)$.

\begin{tabular}{|c|r|r|r|}
\hline Generator i & $\sum \operatorname{Pg}_{\mathrm{ij}}^{\mathrm{o}}(\mathrm{MW})$ & $\sum \Delta \mathrm{Pg}_{\mathrm{ij}}(\mathrm{MW})$ & $\sum \mathrm{Pg}_{\mathrm{ij}}^{1}(\mathrm{MW})$ \\
\hline \hline 1 & 370,000 & 13,000 & 383,000 \\
2 & 366,000 & 19,000 & 385,000 \\
7 & 535,000 & $-135,000$ & 400,000 \\
13 & 1052,000 & 12,000 & 1064,000 \\
15 & 395,000 & 14,000 & 409,000 \\
16 & 280,000 & 15,000 & 295,000 \\
18 & 530,000 & 16,000 & 546,000 \\
21 & 550,000 & 12,000 & 562,000 \\
22 & 330,000 & 16,000 & 346,000 \\
23 & 850,000 & 18,000 & 868,000 \\
\hline
\end{tabular}

\section{Results Obtained with Model 2}

Table III presents similar values as the ones included in each column of Table II, but now considering Model 2 in which one aims at maximizing the overall satisfaction degree, considering the DC model to translate the operation of the network. It was admitted that the maximum reduction of the profit accepted by each generator, $\varepsilon$, was $20 \%$. As a result, the degree of global satisfaction felt by the participants was $14 \%$, due to the large decrease of generation allocated to generator in bus 7 .

\section{Results Obtained with Model 3}

Table IV includes the values for the initially contracted generations (column 2), the deviations imposed by the technical validation study (column 3 ), the resulting contracted generations (column 4), the real generations (column 5) and the contribution of each generator to balance active transmission losses (column $6)$. In this case, there is a difference between the contracted generation and the real generations due to the need to contribute to balance transmission active losses. In this simulation it was admitted that $\varepsilon$ was $20 \%$. The profits obtained in this case lead to a level of global satisfaction felt by the participants of $35 \%$.
The sum of the contributions of each generator to balance active transmission losses corresponds to 104,405 MW. This matches quite well the system transmission losses obtained by the addition of the losses in each branch (104,816 MW). This means that constraint (23) of Model 3 is adequately verified, so that the penalty term in the Simulated Annealing fitness function is neglectable.

Table III - Initially contracted generations $\left(\sum \operatorname{Pg}_{\mathrm{ij}}^{\mathrm{o}}\right)$, deviations $\left(\sum \Delta \mathrm{Pg}_{\mathrm{ij}}\right)$ and final generations $\left(\sum \mathrm{Pg}_{\mathrm{ij}}^{1}\right)$.

\begin{tabular}{|c|c|r|r|}
\hline Generator $\mathrm{i}$ & $\sum \mathrm{Pg}_{\mathrm{ij}}^{\mathrm{o}}(\mathrm{MW})$ & $\sum \Delta \mathrm{Pg}_{\mathrm{ij}}(\mathrm{MW})$ & $\sum \operatorname{Pg}_{\mathrm{ij}}^{1}(\mathrm{MW})$ \\
\hline \hline 1 & 370,000 & 15,000 & 385,000 \\
2 & 366,000 & 19,000 & 385,000 \\
7 & 535,000 & $-135,000$ & 400,000 \\
13 & 1052,000 & $-43,000$ & 1009,000 \\
15 & 395,000 & 6,000 & 401,000 \\
16 & 280,000 & 16,000 & 296,000 \\
18 & 530,000 & 82,000 & 612,000 \\
21 & 550,000 & 15,000 & 565,000 \\
22 & 330,000 & 22,000 & 352,000 \\
23 & 850,000 & 3,000 & 853,000 \\
\hline
\end{tabular}

Table IV- Initially contracted generations $\left(\sum \operatorname{Pg}_{\mathrm{ij}}^{\mathrm{o}}\right)$, deviations $\left(\sum \Delta \mathrm{Pg}_{\mathrm{ij}}\right)$, contracted generations $\left(\sum \mathrm{Pg}_{\mathrm{ij}}^{1}\right)$, total generations $\left(\mathrm{Pg}_{\mathrm{i}}\right)$ and active losses allocated to each generator Ploss $\mathrm{i}_{\mathrm{i}}$.

\begin{tabular}{|r|r|r|r|r|r|}
\hline $\begin{array}{c}\text { Gen } \\
\mathrm{i}\end{array}$ & \multicolumn{1}{c|}{$\begin{array}{c}\sum \mathrm{Pg}_{\mathrm{ij}}^{\mathrm{o}} \\
(\mathrm{MW})\end{array}$} & $\begin{array}{c}\sum \Delta \mathrm{Pg}_{\mathrm{ij}} \\
(\mathrm{MW})\end{array}$ & \multicolumn{1}{c|}{$\begin{array}{c}\sum \mathrm{Pg}_{\mathrm{ij}}^{1} \\
(\mathrm{MW})\end{array}$} & \multicolumn{1}{c|}{$\begin{array}{c}\mathrm{Pg}_{\mathrm{i}} \\
(\mathrm{MW})\end{array}$} & $\begin{array}{c}\text { Ploss }_{\mathrm{i}} \\
(\mathrm{MW})\end{array}$ \\
\hline \hline 1 & 370,000 & $-39,000$ & 331,000 & 336,120 & 5,120 \\
2 & 366,000 & $-13,000$ & 353,000 & 360,580 & 7,580 \\
7 & 535,000 & $-135,000$ & 400,000 & 400,000 & 0,000 \\
13 & 1052,000 & 2,000 & 1054,000 & 1095,801 & 41,801 \\
15 & 395,000 & $-9,000$ & 386,000 & 408,105 & 22,105 \\
16 & 280,000 & 12,000 & 292,000 & 305,535 & 13,535 \\
18 & 530,000 & 27,840 & 557,840 & 558,645 & 0,805 \\
21 & 550,000 & 13,080 & 563,080 & 566,399 & 3,319 \\
22 & 330,000 & $-27,920$ & 302,080 & 308,220 & 6,140 \\
23 & 850,000 & 169,000 & 1019,000 & 1023,000 & 4,000 \\
\hline
\end{tabular}

\section{E. Comparisons and Comments}

The presented Model 1 is very different from the remaining ones given that we are only concerned with the minimization of the squares of the deviations to be imposed to each generation. This may lead to large variations when going from the initial profits to the final ones. On the contrary, Models 2, 3 and 4 aim at adjusting the contracted or scheduled generations so that the generators remain as satisfied as possible. In this sense, the variations of the profits will not be so large, namely because we specify a maximum reduction, $\varepsilon$, that can affect the final profits. To illustrate these aspects, Tables V, VI and VII include the profits associated with the generations. Tables VI and VII also include the degree of satisfaction felt by each participant in the market. 
Table V - Profits of the generators obtained with Model 1 $\left(\mathrm{Cl}_{\mathrm{i}}\right.$ - remuneration, $\mathrm{Cg}_{\mathrm{i}}$ - generation cost and

$\operatorname{Pr} f_{i}$ - profit of the generator i).

\begin{tabular}{|c|r|r|r|}
\hline Gen $\mathrm{i}$ & $\mathrm{Cl}_{\mathrm{i}}(\$)$ & $\mathrm{Cg}_{\mathrm{i}}(\$)$ & $\operatorname{Pr}_{\mathrm{i}}(\$)$ \\
\hline \hline 1 & 4927.500 & 1972.067 & 2955.433 \\
\hline 2 & 5037.000 & 1940.400 & 3096.600 \\
\hline 7 & 4884.000 & 2320.000 & 2564.000 \\
\hline 13 & 13534.900 & 9780.288 & 3754.612 \\
\hline 15 & 4464.000 & 1691.624 & 2772.376 \\
\hline 16 & 3661.000 & 1883.575 & 1777.425 \\
\hline 21 & 7141.600 & 5212.116 & 1929.484 \\
\hline 22 & 6073.000 & 4811.844 & 1261.156 \\
\hline 23 & 4373.000 & 1170.864 & 3202.136 \\
\hline
\end{tabular}

Table VI - Profits of the generators obtained with Model 2 $\left(\operatorname{Pr} \mathrm{f}_{\mathrm{i}}^{\mathrm{o}}\right.$ - initial profit, min $\operatorname{Pr} \mathrm{f}_{\mathrm{i}}$ - minimum profit admitted for the generator $i, \operatorname{Pr} \mathrm{f}_{\mathrm{i}}$ - final profit of the generator $\mathrm{i}, \mu_{\mathrm{i}}$ satisfaction degree felt by generator i).

\begin{tabular}{|c|c|c|c|c|}
\hline Gen $\mathrm{i}$ & $\operatorname{Prf}_{\mathrm{i}}^{\mathrm{o}}(\$)$ & $\min \operatorname{Prf}_{\mathrm{i}}(\$)$ & $\operatorname{Prf}_{\mathrm{i}}(\$)$ & $\mu_{\mathrm{i}}$ \\
\hline \hline 1 & 2881.800 & 2305.440 & 2946.824 & 1 \\
\hline 2 & 2987.476 & 2389.981 & 2995.500 & 1 \\
\hline 7 & 3307.550 & 2646.040 & 2739.000 & 0.14 \\
\hline 13 & 3749.088 & 2999.270 & 3761.558 & 1 \\
\hline 15 & 2673.400 & 2138.720 & 2802.896 & 1 \\
\hline 16 & 1704.800 & 1363.840 & 1707.552 & 1 \\
\hline 18 & 1891.100 & 1512.880 & 1895.856 & 1 \\
\hline 21 & 1222.500 & 978.000 & 1309.675 & 1 \\
\hline 22 & 3072.400 & 2457.920 & 3224.484 & 1 \\
\hline 23 & 3115.000 & 2492.000 & 3200.822 & 1 \\
\hline
\end{tabular}

In this case, the reallocation of the contracted powers mainly affect the satisfaction degree of generator 7 . This is clearly due to the bottleneck imposed by line 7-8, thus illustrating the impact that deficiencies in planning and expansion of transmission systems can impose to market activities.

Table VII - Profits of the generators obtained with Model 3 $\left(\operatorname{Pr} f_{i}^{o}\right.$ - initial profit, min $\operatorname{Pr} f_{i}$ - minimum profit admitted for the generator $i, \operatorname{Pr} \mathrm{f}_{\mathrm{i}}$ - final profit of the generator $\mathrm{i}, \mu_{\mathrm{i}}$ satisfaction degree felt by generator i).

\begin{tabular}{|c|c|c|c|c|}
\hline Gen $\mathrm{i}$ & $\operatorname{Prf}_{\mathrm{i}}^{\mathrm{o}}(\$)$ & $\min \operatorname{Pr} \mathrm{f}_{\mathrm{i}}(\$)$ & $\operatorname{Prf}_{\mathrm{i}}(\$)$ & $\mu_{\mathrm{i}}$ \\
\hline \hline 1 & 2881.800 & 2305.440 & 2713.217 & 0.71 \\
\hline 2 & 2987.476 & 2389.981 & 2803.264 & 0.69 \\
\hline 7 & 3307.550 & 2646.040 & 2874.360 & 0.35 \\
\hline 13 & 3749.088 & 2999.270 & 3570.452 & 0.76 \\
\hline 15 & 2673.400 & 2138.720 & 2751.316 & 1 \\
\hline 16 & 1704.800 & 1363.840 & 1543.328 & 0.53 \\
\hline 18 & 1891.100 & 1512.880 & 1823.216 & 0.82 \\
\hline 21 & 1222.500 & 978.000 & 1429.581 & 1 \\
\hline 22 & 3072.400 & 2457.920 & 2782.311 & 0.53 \\
\hline 23 & 3115.000 & 2492.000 & 3308.867 & 1 \\
\hline
\end{tabular}

When compared with Model 2, Models 3 is clearly more realistic because it represents the network operation conditions using a full AC model. This more accurate representation leads to a more accurate evaluation of the satisfaction degree of the participants and to the possibility of allocating to each generator a contribution to balance transmission active losses. These contributions can be of interest if this ancillary service is remunerated. In this case, this AC application allows the ISO or any other entity to accurately evaluate these contributions and set the corresponding remunerations to the generators.

\section{CONCLUSIONS}

The presented models correspond to optimization tools aiming at performing technical validation studies over sets of buying/selling electricity bilateral contracts. These formulations, namely the one that integrates the $\mathrm{AC}$ power flow model allows us to obtain changes on the values of initially contracted powers avoiding large decreases of the profits of the generating entities. This formulation can still be completed by considering sets of injections communicated by a Pool Market Operator considering that a power system is structured in an hybrid way admitting both bilateral contracts and generation/load bids. This AC formulation presents a clear proximity with OPF type formulations with which system operators are already well acquainted. This means that the installation of this type of applications in control centers could be done with a reduced training effort. The referred optimization models lead to computer applications in which we adopted Simulated Annealing to identify good quality solutions. The adoption of this metaheuristic is justified given its facility of implementation together with the inherent possibility of escaping from local optima.

\section{REFERENCES}

[1] W. Hogan, "Competitive Electricity Market Design: A Wholesale Primer", Center for Business and Government, Harvard University, Massachusetts, December 1998, available in http://faculty-gsb.stanford.edu/wilson/E542.

[2] A. F. Vodjani, C. F. Imparato, N. K. Saini, B. Wollemberg, H. H. Happ, "Transmission Access Issues" IEEE Trans on Power Systems, vol. 11, no. 1, February 1996.

[3] I. J. Pérez-Arriaga, H. Rudnick, W. Stadlin, "International Power System Transmission Open Access Experience", IEEE Trans on Power Systems, vol. 10, no. 1, February 1995.

[4] F. F. Wu, "Coordinated Multilateral Trades for Electric Power Networks", Proceedings of 12th PSCC Conference, Dresden, August 1996.

[5] J. Finney, H. Othman, W. Rutz, "Evaluating Transmission Congestion Constraints in System Planning", IEEE Trans. on Power Systems, vol. 12, no. 3, August 1997.

[6] J. W. M. Cheng, F. D. Galiana, D. T. McGillis, "Studies of Bilateral Contracts with Respect to Steady State Security in a Deregulated Environment", Proceedings of PICA'97, Columbus, Ohio, May 1997.

[7] J. Tomé Saraiva, "A Fuzzy Approach to Power System Planning and Power Transactions in a Competitive Environment", Proceedings of the 35th IEEE Conference on Decision and Control, Kobe, Japan, December 1996.

[8] J. Tomé Saraiva, "An Approach to Enhance Power System Security in Market Environment With Third Party Access", EPSOM'98, Zurich, September 1998.

[9] M. Helder Gomes, "Models to Validate Contracts from a Technical Point of View in Competitive Environment" (in Portuguese), Master Thesis - FEUP, Porto, Portugal, December 2000.

[10]H. J. Zimmermann, "Fuzzy Set Theory and Its Applications", Kluwer Nijhoff, Boston, 1985.

[11]E. Arts, J. Korst, Simulated Annealing and Boltzmann Machines, John Wiley \& Sons, New York, 1990.

[12] IEEE Reliability Test System Task Force, "IEEE Reliability Test System", IEEE Trans. on PAS, vol. 98, no. 6, Nov./Dec. 1979.

Acknowledgements - The work being reported was partially financed by contract PRAXIS 2/2.1/TIT/1634/95. 